\title{
The Impact of Stereotactic or Whole Brain Radiotherapy on Neurocognitive Functioning in Adult Patients with Brain Metastases: A Systematic Review and Meta-Analysis
}

\author{
Eva Elisabeth van Grinsven ${ }^{a} \quad$ Steven H.J. Nagtegaal ${ }^{b} \quad$ Joost J.C. Verhoeff ${ }^{b}$ \\ Martine J.E. van Zandvoort ${ }^{\mathrm{a}, \mathrm{c}}$

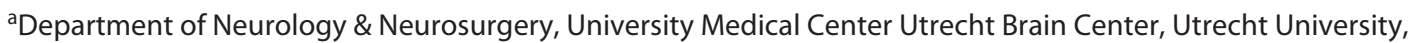 \\ Utrecht, The Netherlands; ' ${ }^{2}$ epartment of Radiation Oncology, University Medical Center Utrecht, Utrecht, \\ The Netherlands; ' ${ }^{\circ}$ Department of Experimental Psychology and Helmholtz Institute, Utrecht University, Utrecht, \\ The Netherlands
}

\section{Keywords}

Brain metastases - Cognition - Neurocognitive functioning · Stereotactic radiosurgery $\cdot$ Whole-brain radiotherapy

\begin{abstract}
Background \& Objectives: Radiotherapy is standard treatment for patients with brain metastases (BMs), although it may lead to radiation-induced cognitive impairment. This review explores the impact of whole-brain radiotherapy (WBRT) or stereotactic radiosurgery (SRS) on cognition. Methods: The PRISMA guidelines were used to identify articles on PubMed and EmBase reporting on objective assessment of cognition before, and at least once after radiotherapy, in adult patients with nonresected BMs. Results: Of the 867 records screened, twenty articles (14 unique studies) were included. WBRT lead to decline in cognitive performance, which stabilized or returned to baseline in patients with survival of at least 9-15 months. For SRS, a decline in cognitive performance was sometimes observed shortly after treatment, but the majority of patients returned to or remained at baseline until a year after treatment. Conclusions: These findings suggest that after WBRT, patients can experience deterioration over a longer period of time. The cognitive side effects of SRS are transient. Therefore, this review advices to choose SRS as this will result in lowest risks for
\end{abstract}

cognitive adverse side effects, irrespective of predicted survival. In an already cognitively vulnerable patient population with limited survival, this information can be used in communicating risks and aid in making educated decisions.

(c) 2021 The Author(s).

Published by S. Karger AG, Basel

\section{Introduction}

Local and systemic treatment for extracranial cancers is improving, leading to longer life expectancy. New challenges arise due to increased survival rates including the development of brain metastases (BMs). BMs occur in at least $10 \%$ of patients diagnosed with cancer and this incidence continues to rise $[1,2]$. BMs are difficult to treat systemically because chemotherapeutic agents barely pass the blood-brain barrier. The median overall survival, despite systemic and focal treatment, is limited spanning months to several years, depending on factors such as lesion number, Karnofsky performance status, and the primary cancer as reflected in GPA calculators [3, 4]. Treatment (shared) decisions in this vulnerable patient population are tailored toward gaining the best disease control while maintaining adequate quality of life (QoL) during the remaining life span.
() 2021 The Author(s)

Published by S. Karger AG, Basel

This is an Open Access article licensed under the Creative Common Attribution-NonCommercial-4.0 International License (CC BY-NC) (http://www.karger.com/Services/OpenAccessLicense), applicable to the online version of the article only. Usage and distribution for commercial purposes requires written permission.
Correspondence to:

Eva Elisabeth van Grinsven, e.e.vangrinsven-5@ umcutrecht.nl 
Table 1. Criteria for assessing the quality of the data of the articles for the review, including reasons for assessing these criteria

\begin{tabular}{|c|c|}
\hline Criteria & Reason \\
\hline 1. Inclusion of $>20$ patients at baseline & (Avoid type II errors for baseline data) \\
\hline 2. $\geq 50 \%$ of patients available for first follow-up measurements & (Avoid type Il errors for follow-up data) \\
\hline $\begin{array}{l}\text { 3. Neurocognitive performance scores corrected to norms for age, sex, and education when } \\
\text { appropriate }\end{array}$ & (Bias by demographical variables) \\
\hline 4. Definition of change in cognitive performance was provided & (Bias by definition of change) \\
\hline 5. Cognitive performance at follow-up time points were adjusted for baseline performance & (Bias by differences in baseline performance) \\
\hline 6. Use of parallel versions of neuropsychological tests for retesting procedures was stated in the article & $\begin{array}{l}\text { (Bias by learning effects due to repeated } \\
\text { administration) }\end{array}$ \\
\hline $\begin{array}{l}\text { 7. Diversity of neurocognitive assessment, assessed by fulfilling ( } 1 / 2 \text { point each): } \\
\text { a. } \geq 3 \text { different neuropsychological tests used } \\
\text { AND } \\
\text { b. } \geq 3 \text { cognitive constructs assessed with test battery }\end{array}$ & (Quality of cognitive testing procedures) \\
\hline
\end{tabular}

Treatment for BMs consists of different (palliative) options, including surgery, chemotherapy, immunotherapy, and radiotherapy [5]. One of the concerns with radiotherapy treatment is how to achieve the optimal balance between maximizing antitumor effects and minimizing possible adverse side effects. The 2 prominent strategies for radiotherapy in BMs are whole-brain radiotherapy (WBRT) and stereotactic radiosurgery (SRS). WBRT is typically advised for patients with more than 3 BMs since treatment covers all brain tissue and has the advantage of sterilizing not-yet visible BMs $[6,7]$. The main disadvantage is that WBRT can lead to radiationinduced tissue damage across the entire brain. SRS has mainly been applied in selected patients with 1 to $3 \mathrm{BMs}$ and a favorable prognosis [8]. During SRS, high precision localized irradiation is delivered to the BMs in a single fraction to maximize local tumor control and minimize the dose to the surrounding, healthy brain tissue.

Patients with BMs compose a vulnerable patient group since a high percentage of patients already experience cognitive impairment before starting radiotherapy as a direct result of BMs but also due to previous cancer treatments [9-11]. Deteriorated cognitive functions have been related to impaired financial, work, and social activities, which are all important in maintaining good QoL and autonomy $[12,13]$. Although the literature on the cognitive changes after radiotherapy has been reviewed both for WBRT and SRS separately $[14,15]$, to date no publication exists comparing WBRT with SRS in relation to the cognitive outcome after treatment. Since SRS is increasingly being favored over WBRT in current practice [16], we performed a systematic review on changes in cognitive functioning provoked by either WBRT or SRS in adult patients with nonresected BMs to gain insight on whether current evidence regarding cognitive side effects substantiates contemporary shifts in treatment preference.

\section{Methods}

\section{Search Strategy}

The Preferred Reporting Items for Systematic Reviews and MetaAnalyses (PRISMA) guidelines were used in conducting and reporting this systematic review [17]. We reviewed all published articles on the neurocognitive effects of WBRT or SRS in adult patients with BMs from 1 January 1950 until 4 January 2021. The search strategy combined terms for BMs, radiotherapy, and cognition and was developed for PubMed and adapted for Embase. The complete search strings can be found in online suppl. material 1; for all online suppl. material, see www.karger.com/doi/10.1159/000518848. Additionally, reference lists were manually screened for potentially relevant studies. Articles were screened by 2 researchers (E.E.G. and S.H.J.N.) and disagreement was resolved through consensus meetings. The screening of the studies was facilitated by Covidence systematic review software (Veritas Health Innovation, Melbourne, VIC, Australia). Reasons for exclusion were documented for each article.

\section{Eligibility}

The search was confined to articles in English and Dutch. Studies were selected in which objective neurocognitive assessment was performed at baseline (defined as any time point between presentation of the BMs and start of radiotherapy) and at least once after radiotherapy in adult patients with BMs. Only objective cognitive measurements were included since self-reports may be biased due to impairments caused by the BMs and (previous) cancer treatments [18]. Moreover, subjective cognitive complaints do not represent underlying cognitive deficits per se and may be more indicative of psychological distress than actual cognitive impairment [19, 20]. Studies solely utilizing short neurocognitive-screening tools, such as the Mini-Mental Status Examination, were excluded since these tests lack the sensitivity to detect subtle changes in cognitive functioning expected to be present after radiotherapy [21-23]. Furthermore, all articles including patients with resected BMs were excluded since coacting cortical tissue damage adjacent to the resection site can influence cognitive performance. Studies investigating the influence of treatments concurrent to radiotherapy (e.g., memantine) that did not report on a radiotherapy-only control group were also excluded. Case reports, reviews, commentaries, editorials, and protocols were excluded. If multiple articles reported on the same dataset, the results were combined and reviewed as one cohort. 
Table 2. Assessment of data quality for each included study listed from highest to lowest quality

\begin{tabular}{|c|c|c|c|c|c|c|c|c|c|}
\hline $\begin{array}{l}\text { Type of } \\
\text { RT }\end{array}$ & $\begin{array}{l}\text { Criteria } \\
\text { authors }\end{array}$ & $\begin{array}{l}\geq 20 \\
\text { patients }\end{array}$ & $\begin{array}{l}\geq 50 \% \text { at the first } \\
\text { follow-up }\end{array}$ & $\begin{array}{l}\text { Corrected to } \\
\text { norms }\end{array}$ & $\begin{array}{l}\text { Definition } \\
\text { provided }\end{array}$ & $\begin{array}{l}\text { Adjusted for } \\
\text { baseline }\end{array}$ & $\begin{array}{l}\text { Parallel } \\
\text { tests }\end{array}$ & $\begin{array}{l}\text { Diversity } \\
\text { NCA }\end{array}$ & $\begin{array}{l}\text { Overall } \\
\text { quality }\end{array}$ \\
\hline \multirow[t]{9}{*}{ WBRT } & Mehta et al. $[7,18,38,74]$ & + & + & + & + & + & - & + & 6 good \\
\hline & Gondi et al. [26] & + & + & - & + & + & + & $+/-$ & 5.5 good \\
\hline & Westover et al. [41] & + & + & - & $+/-$ & + & + & + & $5.5 \mathrm{good}$ \\
\hline & Saito et al. [28] & + & + & - & + & + & + & - & 5 good \\
\hline & Deng et al. [35] & + & + & - & + & + & - & + & 5 good \\
\hline & Zhu et al. [40] & + & + & - & + & + & - & + & 5 good \\
\hline & Zhan et al. [39] & + & + & - & + & + & - & & 4 medium \\
\hline & Onodera et al. [25] & + & + & + & - & - & - & + & 4 medium \\
\hline & Cheng et al. [34] & + & + & - & - & - & - & + & 3 medium \\
\hline \multirow[t]{7}{*}{ SRS } & Chang et al. [29] & - & + & + & + & + & + & + & 6 good \\
\hline & Brown et al. [32] & + & + & + & + & + & - & + & $6 \mathrm{good}$ \\
\hline & Chang et al. [31] & + & + & - & + & + & - & + & 5 good \\
\hline & Habets et al. [30, 43] & + & - & + & + & + & - & + & 5 good \\
\hline & Minniti et al. [42] & + & + & - & + & + & + & - & 5 good \\
\hline & Onodera et al. [25] & - & + & + & - & - & - & + & 3 medium \\
\hline & Kirkpatrick et al. [24] & + & - & - & - & - & - & $+/-$ & 1.5 low \\
\hline
\end{tabular}

NCA, neurocognitive assessment; RT, radiotherapy; SRS, stereotactic radiosurgery; WBRT, whole-brain radiotherapy. + Indicates 1 point awarded for that criterion. - Indicates no points. $+/-0.5$ points.

Data Extraction and Analysis

The follow-up time points were converted to units of "months after radiotherapy." To aid comparability across studies and following the classification used in previous studies, time points were clustered: short-term follow-up 1-4 months after radiotherapy, midterm follow-up 5-8 months after radiotherapy, and long-term follow-up 9-15 months after radiotherapy. Baseline measurements always refer to the assessment before start of radiotherapy treatment. Additionally, neuropsychological tests were attributed to cognitive constructs in a data-driven classification, based on the subdivision as reported in the majority of the included studies (online suppl. material 2). Data were collected from text, tables, and figures from the articles and then tabulated. Missing data points were excluded from analyses and changes in sample size due to attrition were considered. For meta-analysis of the incidence of cognitive decline compared to baseline performance, we used the inverse variance method in a DerSimonian-Laird random effects model. For individual studies Clopper-Pearson confidence intervals were calculated. Heterogeneity between studies was assessed using Cochran's $Q$ test and the $I^{2}$ statistic. Statistical analyses were performed with $\mathrm{R}$ 3.5.1 open-source software with the "meta" package (http:// www.R-project.org).

\section{Data Quality}

A critical appraisal of the included studies was performed to assess data quality as reported in the articles, for which a checklist consisting of 7 criteria were constructed (shown in Table 1). One point was awarded if the criterion was met and zero points if not or if it was unclear based on the available information. A maximum score of 7 points could be obtained. A score between 5 and 7 indicates good to high quality, 3 and 4 medium quality, and scores below 2 indicate low quality.

\section{Results}

\section{Study Inclusion}

The initial search yielded 867 unique articles. After applying the in- and exclusion criteria, 20 articles reporting on 14 original datasets were included in this review (shown in Fig. 1). The majority of these studies were rated as good to high quality (shown in Table 2). The one study rated as low quality was excluded from further analysis [24]. Study and baseline patient characteristics and the main conclusions of the selected articles are shown in Tables 3 and 4, respectively. Patient numbers varied considerably across studies with a median sample size of 81 (range: 20-208) and 35 (range: 7-111) at baseline for the WBRT and SRS studies, respectively. In total, 751 WBRT patients were included and 300 SRS patients. Since data on the incidence of cognitive decline were absent in some articles, the meta-analysis could only be performed for those studies that reported on these data.

\section{Baseline Cognitive Performance}

Data on baseline cognitive performance before WBRT were solely explicitly reported for the Mehta et al. [18] study $(N=208)$. The other included studies reported relative scores to an unreported baseline. Before starting WBRT, $91 \%$ of the patients displayed cognitive impairment $(Z$-score $\leq 1.5)$ on $\geq 1$ neuropsychological test and $42 \%$ on $\geq 4$ neuropsychological tests. Fine motor coordination was impaired in 63-65\%, learning and memory (L\&M) in $21-60 \%$, executive function (EF) in $44 \%$, and verbal fluency in $33 \%$. Lower baseline cognitive perfor- 


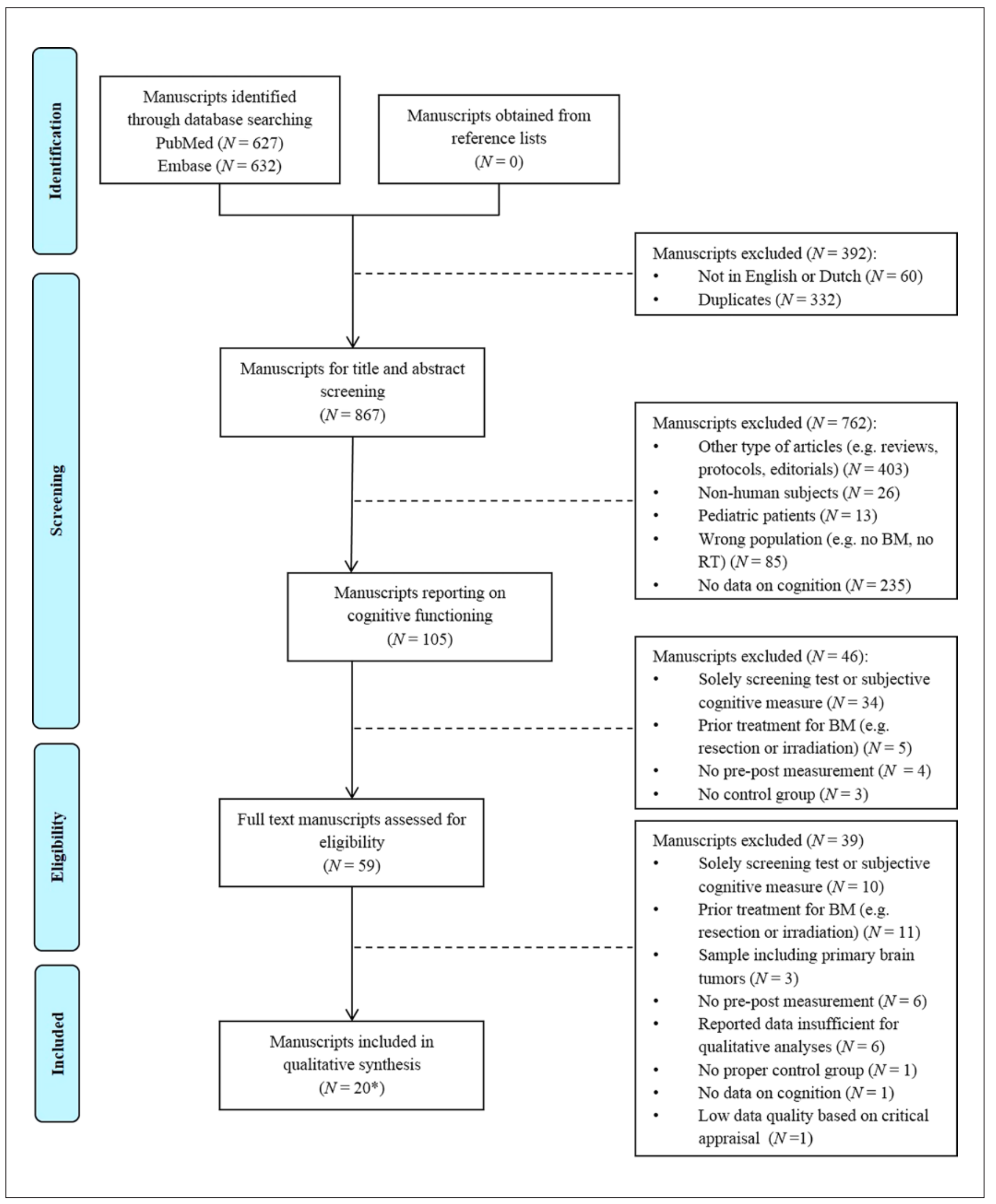

Fig. 1. PRISMA flow chart illustrating the systematic process conducted to identify the articles included in this review. 14 original datasets*. PRISMA, Preferred Reporting Items for Systematic Reviews and Meta-Analyses. 


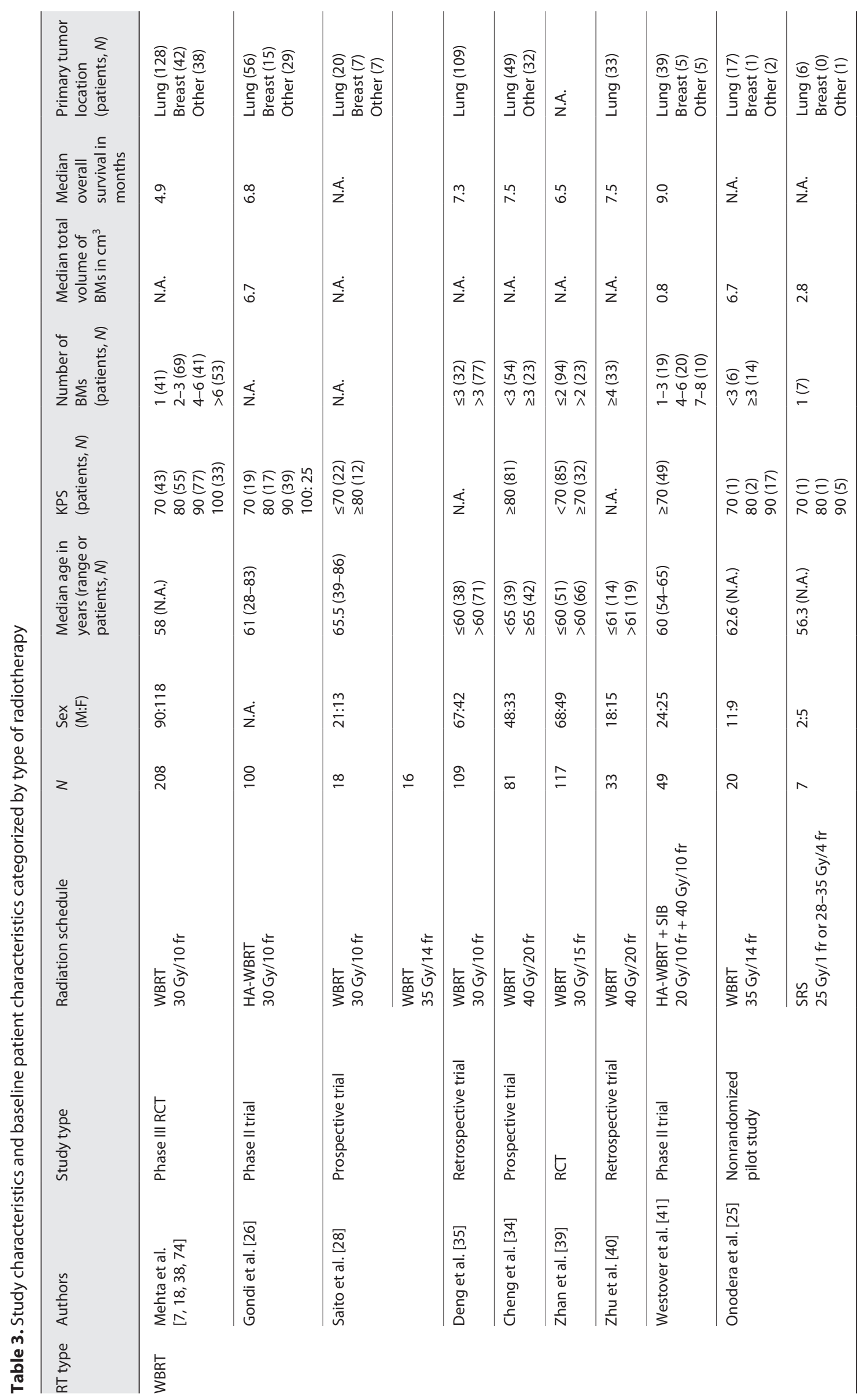




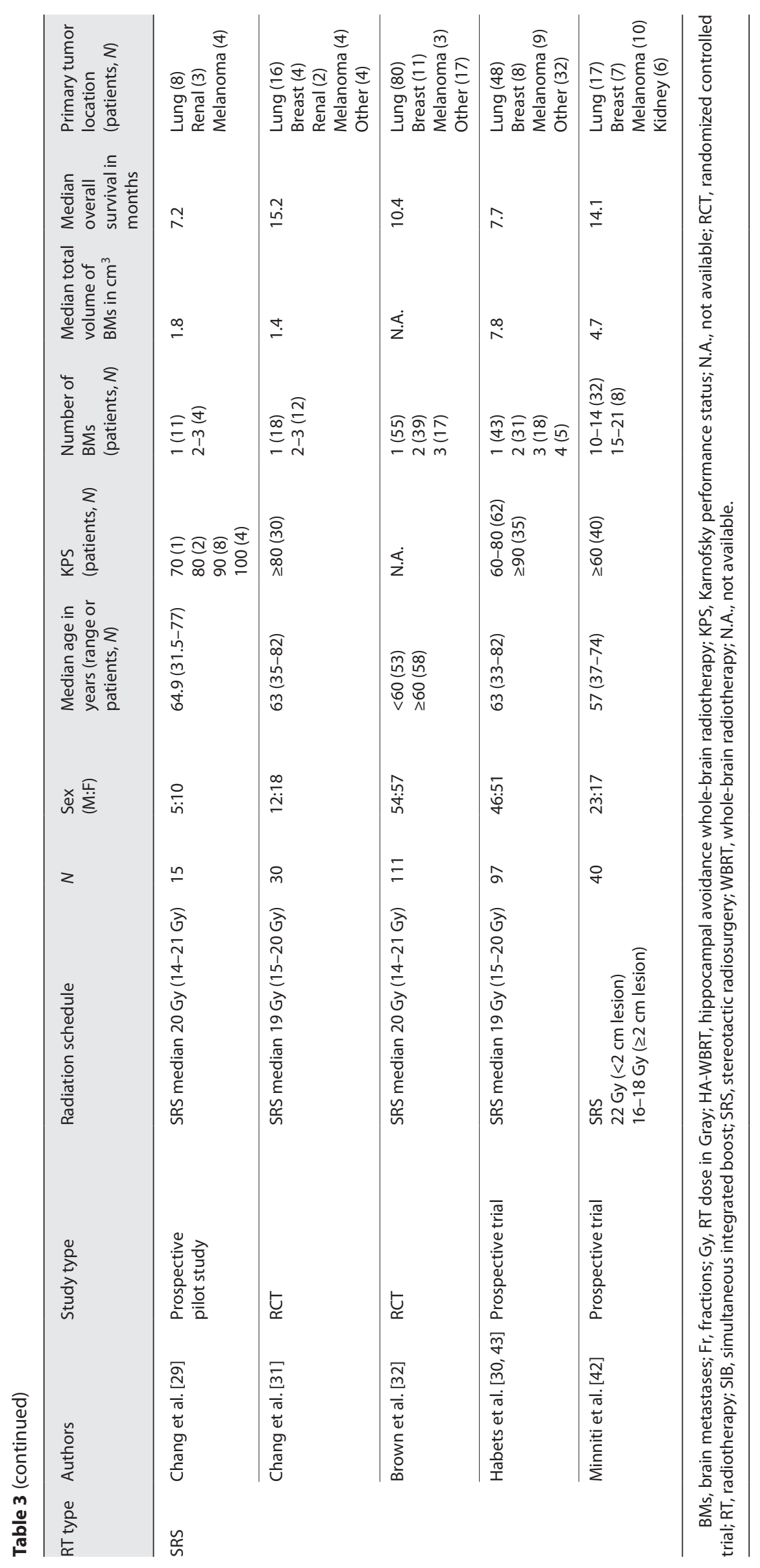


Table 4. Main message of the studies categorized by type of radiotherapy

\begin{tabular}{|c|c|c|c|c|c|}
\hline $\begin{array}{l}\text { RT } \\
\text { type }\end{array}$ & Authors & $\begin{array}{l}\text { Patients, } \\
N\end{array}$ & $\begin{array}{l}\text { Time points NCF } \\
\text { assessed in } \\
\text { months after RT }\end{array}$ & $\begin{array}{l}\text { Definition of } \\
\text { cognitive } \\
\text { change }\end{array}$ & Main message \\
\hline \multirow[t]{3}{*}{ WBRT } & $\begin{array}{l}\text { Mehta et al. } \\
{[7,18,38,74]}\end{array}$ & $\begin{array}{l}208 \\
135 \\
63-75^{*} \\
43-46^{*} \\
9\end{array}$ & $\begin{array}{l}\text { T0 } \\
\text { T1 } \\
\text { T2 } \\
\text { T3 } \\
\text { T4 } \\
\text { T5 } \\
\text { T6 } \\
\text { T9 } \\
\text { T12 } \\
\text { T15 } \\
\text { T18 }\end{array}$ & $\begin{array}{l}\leq 2 \text { SD change in } \\
\text { average } Z \text {-score }\end{array}$ & $\begin{array}{l}\text { T3: Most patients deteriorate on fine motor coordination and least patients on } \\
\text { verbal fluency } \\
\text { T4: Significant deterioration compared to T0 on L\&M and verbal fluency } \\
\text { T15: Significant improvement compared to T0 on verbal fluency, fine motor } \\
\text { coordination, and information processing speed }\end{array}$ \\
\hline & Gondi et al. [26] & $\begin{array}{l}100 \\
53 \\
42 \\
29\end{array}$ & $\begin{array}{l}\text { T0 } \\
\text { T2 } \\
\text { T4 } \\
\text { T6 }\end{array}$ & $\mathrm{RCl}$ & $\begin{array}{l}\text { T2: 7-18\% mean decline from T0 in L\&M performance } \\
\text { T4: In a subset of } 33 \text { patients with T0 MRI, the change in L\&M performance was } \\
\text { correlated with BMs volume (immediate and delayed recall), age (immediate } \\
\text { recall), and volume of white matter injuries pre-treatment (recognition) } \\
\text { T6: Certain aspects of L\&M declined (delayed recall), while others remained } \\
\text { stable (immediate recall and recognition). The mean relative decline from T0 to } \\
\text { T6 was } 0-3 \%\end{array}$ \\
\hline & Saito et al. [28] & $\begin{array}{l}34 \\
34 \\
19\end{array}$ & $\begin{array}{l}\text { T0 } \\
\text { T4 } \\
\text { T8 }\end{array}$ & $\mathrm{RCl}$ & $\begin{array}{l}\text { T4: L\&M deteriorated significantly compared to T0 in those who only completed } \\
\text { T0 and T4 assessments. In total, } 27-33 \% \text { of the patients had deteriorated } \\
\text { T8: On an average, stable cognitive performance was observed on L\&M in } \\
\text { subgroup completing assessments at all } 3 \text { time points. Of this subgroup, } 11- \\
26 \% \text { had deteriorated L\&M performance compared to baseline }\end{array}$ \\
\hline \multirow[t]{5}{*}{ WBRT } & & $\begin{array}{l}109 \\
87-89^{*} \\
61-64^{*} \\
34-36^{*}\end{array}$ & $\begin{array}{l}\text { T0 } \\
\text { T3 } \\
\text { T5 } \\
\text { T7 }\end{array}$ & $\mathrm{RCl}$ & $\begin{array}{l}\text { T3: } 22-38 \% \text { of the patients deteriorated on overall cognitive performance, with } \\
\text { greatest deterioration on L\&M ( } 22-37 \%), E F(38 \%) \text { and verbal fluency ( } 32 \%) \\
\text { T5: } 40-55 \% \text { of the patients deteriorated on at least one cognitive task, with } \\
\text { greatest deterioration on L\&M (52-55\%) and verbal fluency }(53 \%) \\
\text { T7: } 47-61 \% \text { of the patients deteriorated on at least one cognitive task, with } \\
\text { greatest deterioration on EF }(61 \%) \text { and verbal fluency }(59 \%)\end{array}$ \\
\hline & Deng et al. [35] & $\begin{array}{l}81 \\
81\end{array}$ & $\begin{array}{l}\text { T0 } \\
\text { T1 }\end{array}$ & N.A. & $\begin{array}{l}\text { T1: Significantly decreased performance compared to T0 on global cognitive } \\
\text { performance, attention, verbal fluency, and event-based prospective memory. } \\
\text { Stable performance on time-based prospective memory }\end{array}$ \\
\hline & Cheng et al. [34] & $\begin{array}{l}117 \\
91 \\
54\end{array}$ & $\begin{array}{l}\text { T0 } \\
\text { T1 } \\
\text { T2 } \\
\text { T3 } \\
\text { T4 } \\
\text { T5 } \\
\text { T6 }\end{array}$ & $\mathrm{RCl}$ & $\begin{array}{l}\text { T3: } 19 \% \text { of the patients deteriorated on L\&M performance } \\
\text { T6: } 35 \% \text { of the patients deteriorated on L\&M performance }\end{array}$ \\
\hline & Zhan et al. [39] & $\begin{array}{l}33 \\
29-31^{*} \\
26-29 * \\
22-26 *\end{array}$ & $\begin{array}{l}\text { T0 } \\
\text { T3 } \\
\text { T6 } \\
\text { T9 }\end{array}$ & $\mathrm{RCl}$ & $\begin{array}{l}\text { T3: Deteriorated cognitive performance was found on L\&M, EF, and verbal } \\
\text { fluency in } 19 \%, 29 \% \text {, and } 28 \% \text { of the patients, respectively } \\
\text { T6: Deteriorated cognitive performance was found on L\&M, EF, and verbal } \\
\text { fluency in } 48 \%, 48 \% \text {, and } 50 \% \text { of the patients, respectively } \\
\text { T9: Deteriorated cognitive performance was found on L\&M, EF, and verbal } \\
\text { fluency in } 50 \%, 58 \% \text {, and } 57 \% \text { of the patients, respectively }\end{array}$ \\
\hline & Zhu et al. [40] & $\begin{array}{l}47 \\
18 \\
8 \\
5\end{array}$ & $\begin{array}{l}\text { T0 } \\
\text { T3 } \\
\text { T6 } \\
\text { T9 } \\
\text { T12 }\end{array}$ & $\begin{array}{l}\leq 1 \mathrm{SD} \text { decline } \\
\text { from the mean }\end{array}$ & $\begin{array}{l}\text { T3: Compared to T0, L\&M performance declined in } 17 \% \text { of the patients on } \\
\text { delayed recall with a mean decline of } 11 \% \text {. No significant changes were found } \\
\text { on the other cognitive tasks, but there were large variations } \\
\text { T6: Mean L\&M performance (delayed recall) recovered to pre-treatment values }\end{array}$ \\
\hline
\end{tabular}


Table 4 (continued)

\begin{tabular}{|c|c|c|c|c|c|}
\hline $\begin{array}{l}\text { RT } \\
\text { type }\end{array}$ & Authors & $\begin{array}{l}\text { Patients, } \\
N\end{array}$ & $\begin{array}{l}\text { Time points NCF } \\
\text { assessed in } \\
\text { months after RT }\end{array}$ & $\begin{array}{l}\text { Definition of } \\
\text { cognitive } \\
\text { change }\end{array}$ & Main message \\
\hline WBRT & $\begin{array}{l}\text { Westover et al. } \\
{[41]} \\
\text { Onodera et al. } \\
{[25]}\end{array}$ & $\begin{array}{l}20 \\
17 \\
14 \\
9\end{array}$ & $\begin{array}{l}\text { T0 } \\
\text { T4 } \\
\text { T8 } \\
\text { T12 }\end{array}$ & N.A. & $\begin{array}{l}\text { T4: Patients receiving WBRT deteriorated significantly compared to T0 on L\&M } \\
\text { (delayed recall). Additional analysis showed only patients with a brain edema } \\
\text { volume } \geq 16.8 \text { cc. Decreased on L\&M (delayed recall) and EF } \\
\text { T8: Patients receiving WBRT deteriorated significantly compared to T0 and T4 on } \\
\text { L\&M (immediate recall) Improvements in immediate and delayed recall at T8 } \\
\text { compared to T4 were only observed in patients with a }<4.0 \text { cc total volume of } \\
\text { BM at T0 } \\
\text { T12: In the subgroup of patients followed for at least } 12 \text { months, L\&M (delayed } \\
\text { recognition) had significantly declined compared to T0 at both T4 and T12. This } \\
\text { subgroup also had significantly declined EF at T4 compared to T0, with a similar } \\
\text { trend at T12. Additionally, L\&M (immediate recall) had returned to baseline } \\
\text { values at T12 after a significant improvement at T8 } \\
\text { No changes in verbal fluency, information processing speed, or on cognitive } \\
\text { screening measure at any time point }\end{array}$ \\
\hline \multirow[t]{3}{*}{ SRS } & & $\begin{array}{l}7 \\
5 \\
5 \\
4\end{array}$ & $\begin{array}{l}\text { T0 } \\
\text { T4 } \\
\text { T8 } \\
\text { T12 }\end{array}$ & N.A. & $\begin{array}{l}\text { T4-12: SRS group had no change in cognitive performance for any tested } \\
\text { cognitive construct over the entire study period }\end{array}$ \\
\hline & & $\begin{array}{l}15 \\
13 \\
5\end{array}$ & $\begin{array}{l}\text { T0 } \\
\text { T1 } \\
\text { T2 } \\
\text { T3 } \\
\text { T4 } \\
\text { T5 } \\
\text { T7-9 } \\
\text { T10-12 }\end{array}$ & $\mathrm{RCl}$ & $\begin{array}{l}\text { 1: All patients declined on } \geq 1 \text { neuropsychological test and } 54 \% \text { on } \geq 2 \text { tests, with } \\
\text { decline in } L \& M(54 \%) \text { and fine motor coordination }(46 \%) \text { most common. } \\
\text { Improvements were also observed, mostly on EF ( } 38 \%) \text {, verbal fluency }(15 \%) \text {, } \\
\text { fine motor coordination ( } 15 \%) \text {, and information processing speed }(15 \%) \\
\text { T7-9: Stable or improved cognitive performance was found for } 80 \% \text { of the } \\
\text { patients for L\&M and } 60.0 \% \text { for EF and fine motor coordination }\end{array}$ \\
\hline & Chang et al. [29] & $\begin{array}{l}30 \\
20\end{array}$ & $\begin{array}{l}\text { T0 } \\
\text { T1 } \\
\text { T2 } \\
\text { T4 } \\
\text { T6 } \\
\text { T12 } \\
\text { T15 } \\
\text { T18 }\end{array}$ & $\mathrm{RCl}$ & $\begin{array}{l}\text { T4: Most cognitive decline on tests for L\&M ( } 20 \% \text { of the patients on total recall). } \\
\text { The mean posterior probability of decline was } 24 \% \text { for total recall, } 6 \% \text { for } \\
\text { delayed recall end } 0 \% \text { for delayed recognition. Analysis were also performed for } \\
\text { other cognitive tests but might have been underpowered since the trial was } \\
\text { stopped prematurely due to significant larger probability of decline on L\&M } \\
\text { (total recall) after } 4 \text { months in the SRS + WBRT versus the SRS alone group } \\
\text { T6: The mean posterior probability of decline on total recall was } 8 \%\end{array}$ \\
\hline \multirow[t]{3}{*}{ SRS } & Chang et al. [31] & $\begin{array}{l}111 \\
63 \\
10-12^{*} \\
12-14^{*} \\
9-10^{*}\end{array}$ & $\begin{array}{l}\text { T0 } \\
\text { T1.5 } \\
\text { T3 } \\
\text { T6 } \\
\text { T9 } \\
\text { T12 }\end{array}$ & $\geq 1 \mathrm{SD}$ & $\begin{array}{l}\text { T3: } 64 \% \text { of the patients showed cognitive deterioration on } \geq 1 \text { test compared to } \\
T=0 \text {. Most patients deteriorated on L\&M (recognition) performance }(23 \%) \text { and } \\
\text { information processing speed (19\%) and least on verbal fluency ( } 2 \%) \\
\text { T6: In those patients surviving at least } 12 \text { months, } 50 \% \text { deteriorated on at least } 1 \\
\text { test compared to } T=0 \text {. Most patients deteriorated on L\&M (delayed recall) } \\
\text { performance ( } 33 \%) \text { and none deteriorated on information processing speed } \\
\text { T9: In those patients surviving at least } 12 \text { months, } 50 \% \text { deteriorated on at least } 1 \\
\text { test compared to } T=0 \text {. Most patients deteriorated on L\&M (delayed recall and } \\
\text { discrimination index) performance (both } 23 \% \text { ) and none on verbal fluency } \\
\text { T12: In those patients surviving at least } 12 \text { months, } 60 \% \text { deteriorated on at least } \\
1 \text { test compared to } T=0 . \text { Most deteriorated on } L \& M \text { (delayed recall) } \\
\text { performance }(20 \%) \text { and none on verbal fluency }\end{array}$ \\
\hline & Brown et al. [32] & $\begin{array}{l}97 \\
39 \\
29\end{array}$ & $\begin{array}{l}\text { T0 } \\
\text { T3 } \\
\text { T6 }\end{array}$ & $\begin{array}{l}\leq 1.5 \text { SD mean of } \\
\text { healthy controls }\end{array}$ & $\begin{array}{l}\text { T6: The majority of the patients maintained their pre-treatment levels of } \\
\text { cognitive performance over the entire study period. Only verbal fluency } \\
\text { performance showed trend towards improvement }\end{array}$ \\
\hline & $\begin{array}{l}\text { Habets et al. [30, } \\
43]\end{array}$ & $\begin{array}{l}38 \\
32 \\
26 \\
21\end{array}$ & $\begin{array}{l}\text { T0 } \\
\text { T3 } \\
\text { T6 } \\
\text { T12 }\end{array}$ & $\mathrm{RCl}$ & $\begin{array}{l}\text { T3: Compared to T0, L\&M performance declined in } 13 \%, 16 \% \text {, and } 19 \% \text { of the } \\
\text { patients on immediate recall, recognition, and delayed recall. The mean decline } \\
\text { varied between } 10 \text { and } 14 \% \\
\text { T6: Compared to T0, L\&M performance declined in } 12 \%, 15 \% \text { and } 15 \% \text { of the } \\
\text { patients on immediate recall, recognition and delayed recall } \\
\text { The mean decline varied between } 5 \text { and } 9 \% \\
\text { T12: Compared to T0 L\&M performance declined in } 5 \%, 10 \% \text { and } 14 \% \text { of the } \\
\text { patients on immediate recall, recognition and delayed recall. The mean decline } \\
\text { varied between } 2 \text { and } 5 \%\end{array}$ \\
\hline
\end{tabular}

$T$, time point in months after radiotherapy; N.A., not available; NCF, neurocognitive functioning; RCl, reliable change index; RT, radiotherapy; SD, standard deviations; SRS, stereotactic radiosurgery; WBRT, whole-brain radiotherapy; L\&M, learning and memory; EF, executive function. * Ranges in patient numbers are caused by different numbers of patients completing the different cognitive tests during the study-procedures. 
mance correlated with higher total BMs volume at baseline but not with number of BMs $[18,25]$. On the contrary, in another study, neither the volume of BMs nor volume of white matter injury correlated with L\&M performance before radiotherapy in a subset of patients [26, 27]. Patients with a KPS of $\geq 80$ and patients $\leq 65$ years performed better at baseline on subtests of L\&M [28].

Data on the incidence of baseline cognitive impairment before SRS were explicitly reported for the pilot study by Chang et al. [29, 31] $(N=15)$ and by Habets et al. $[30,43](N=77)[29,30]$. Pre-radiotherapy, 53-67\% of patients had cognitive impairment $(Z$-score $\leq 1.5 \mathrm{SD})$ on $\geq 1$ neuropsychological test. At baseline, EF was impaired in $47 \%$ of the patients, fine motor coordination in $40 \%$, L\&M in $31 \%$, visual memory and visuoconstruction in $22 \%$, information processing speed in $10 \%$, and verbal fluency in $7 \%$. Before SRS, the mean $Z$-scores of both the Chang et al. [29, 31] $(N=30)$ and the Brown et al. [32] cohort $(N=111)$ were impaired $[31,32]$. The worst group performance was observed on tasks for EF and information processing speed. Patients with a baseline BMs volume of $>3 \mathrm{~cm}^{3}$ performed worse on attention than those with smaller lesion volumes [29]. Similarly, Onodera et al. [25] reported higher total lesion volume but not the number of BMs at baseline corresponded with worse cognitive performance, while Habets et al. [30, 43] reported no significant association with BMs volume $[25,30]$.

\section{Post-Radiotherapy Cognitive Performance}

At short-term follow-up (1-4 months), the majority of the WBRT studies ( $N=455$ patients) found consistent declines in cognitive performance on most cognitive constructs $[18,25,26,28,33-40]$. Overall, between 19 and $37 \%$ of the patients deteriorated regarding L\&M performance. Gondi et al. [26] found that patients treated with hippocampal avoidance WBRT (HA-WBRT) had significantly less mean relative decline in $\mathrm{L} \& \mathrm{M}$ performance compared to the patients of Mehta et al. [7, 18] who received conventional WBRT (7\% vs. $30 \%$, respectively) $[18,26]$. The change in L\&M performance was correlated to pre-treatment BMs volume, age, and the volume of white matter injuries [27]. Other impaired cognitive constructs in the WBRT studies were EF (29-38\%), fine motor coordination (31\%), information processing speed (28\%), and verbal fluency (7$32 \%)$. Even though Westover et al. [41] observed a decline in $17 \%$ of their patients $(N=18)$ regarding L\&M performance, on the group level, no significant changes from baseline were found for the other cognitive constructs [41]. Nevertheless, large variations in mean relative change were found for all cognitive constructs (L\&M, information processing speed, EF, and verbal fluency).

At midterm follow-up (5-8 months), the results were more variable. The 29 patients who received HA-WBRT had a mere relative decline of $0-3 \%$ on multiple tests for
L\&M at midterm follow-up compared to baseline [26, 33]. Similarly, patients who survived more than 6 months after HA-WBRT with simultaneous integrated boost recovered to baseline scores regarding L\&M performance [41]. On the contrary, performance on most cognitive tasks declined in at least 114 patients who received conventional WBRT $[35,39,40]$. L\&M performance was most often affected, with $53 \%$ of the patients showing decline [35]. Moreover, the percentage of patients with declined performance increased from $19 \%$ at short-term to $35 \%$ at midterm follow-up [39]. Although group performance declined compared to both baseline and shortterm follow-up when considering all 17 patients in the Onodera et al. [25] cohort, improvements were observed in a subgroup of patients with a baseline BMs volume of $<4.0 \mathrm{~cm}^{3}$ and in BMs patients surviving at least 12 months [25]. A similar trend was reported by Saito et al. [28] where the subgroup surviving at least 8 months $(N=19)$ had stable L\&M performance over time [28]. Thus, most patients further decreased in cognitive performance at midterm follow-up, but in a subgroup of patients, stable or improved cognitive performance was observed over time.

At long-term follow-up (9-15 months), performance on most cognitive constructs either returned to baseline values or remained stable compared to midterm followup. Mehta et al. $[7,18]$ found slight improvements or stable functioning $(N=9)$ regarding verbal fluency, information processing speed, and fine motor coordination compared to baseline [18]. In the Zhu et al. [40] cohort $(N=22), 48 \%$ of the patients had deteriorated on L\&M performance, which is comparable to the $50 \%$ at midterm follow-up, suggesting most patients had stable cognitive performance from mid- to long-term follow-up [40]. Similarly, for the 9 patients in the Onodera et al. [25] study, performance on tests for verbal fluency and information processing speed remained stable over the entire study. L\&M performance (delayed recognition) significantly declined compared to both baseline and midterm follow-up, and a similar trend was seen for EF. Forest plots of the incidence of patients with cognitive decline for each construct at each time point are presented in online suppl. material 3. The analyses indicated significant heterogeneity between studies for L\&M at midterm follow-up. The meta-analysis suggests an increase in the amount of patients with cognitive decline over time until midterm follow-up, with a (relatively) stable or even lower incidence was found at long-term (shown in Fig. 2a).

In accordance with the results described above, Gondi et al. [26] reported a trend toward deteriorated performance on L\&M tasks 1 month after WBRT, which stabilized and reverted back to baseline values after that time point. In the Mehta et al. [7, 18] study, cohort time to neurocognitive deterioration was on average shortest for 


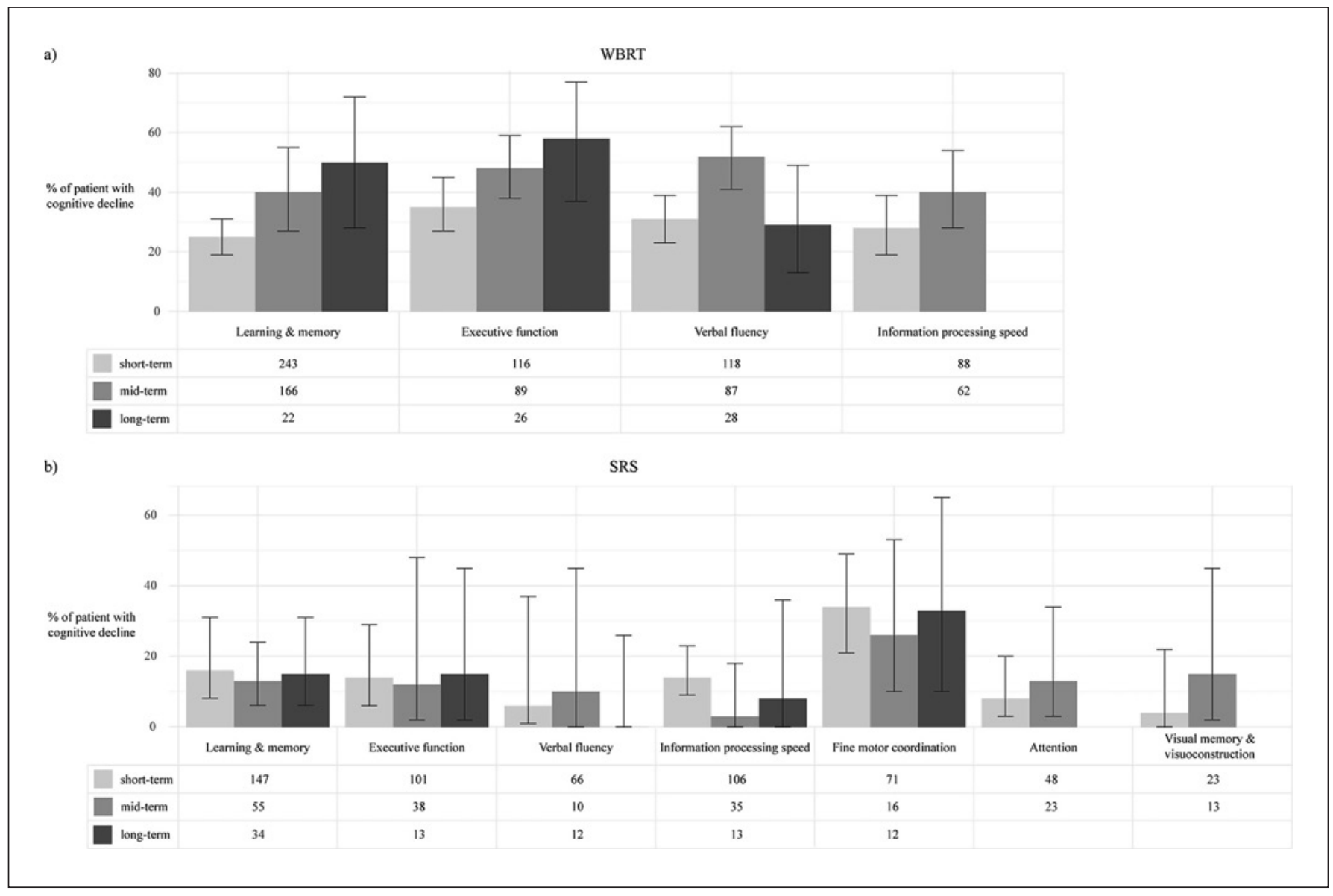

Fig. 2. Bar charts illustrating the pooled incidence of declined cognitive performance compared to baseline on the different cognitive constructs at different time points (a) WBRT and (b) SRS. The error bars display the 95\% CIs. The table below the chart displays the number of patients for whom these data were available. CIs, confidence intervals.

fine motor coordination, L\&M, and EF [18]. Additionally, they found that time to neurocognitive deterioration significantly differed between patients showing a volume reduction below or above $45 \%$ after 2 months, with patients with more volume reduction (classified as good responders) having a longer time to deterioration on fine motor coordination.

At short-term follow-up (1-4 months) after SRS, the majority of studies reported a decline in cognitive performance when compared to baseline. Overall, declined performance was most common regarding L\&M (23-54\%) and fine motor coordination (35-46\%) [29, 31, 32]. Similarly, between 13 and $19 \%$ of the patients in the Minniti et al. [42] cohort $(N=32)$ showed a mean decline of 10 $14 \%$ from baseline. For the other assessed cognitive constructs (verbal fluency, attention, information processing speed and EF) the amount of patients in the Chang et al. $[29,31]$ study that had deteriorated were balanced out by the patients that had improved [29]. Contrarily, 18\% showed a decline in EF in the other study by Chang et al. $[29,31](N=20)$ and $17 \%$ on information processing speed in the study by Brown et al. [32] $(N=60)[31,32]$. Both studies found least deterioration on tasks for attention $(6 \%)$ and verbal fluency $(2 \%)$. The 2 other studies assessing short-term cognitive performance found no change in cognition compared to baseline $[25,30]$. For example, it was reported that $78-100 \%$ of the patients $(N=19)$ had stable performance regarding the different cognitive constructs, where the small percentage of patients that showed declined cognitive performance on the different tests $(3-8 \%)$ was balanced by those that improved (3-17\%) [30]. At both midterm (5-8 months) and long-term follow-up (9-12 months), all studies reported either stable or slightly improved cognitive performance compared to baseline performance [25, 29-32, 42, 43]. To illustrate, the percentage of patients with declined performance on L\&M decreased at both mid- and long-term follow-up compared to short-term [42]. Additionally, the mean decline reduced to $2-5 \%$ at long-term follow-up compared to $10-14 \%$ at short-term, suggesting that both the number of patients as well as the severity of the cognitive decline decreased. 
Forest plots of the incidence of patients with cognitive decline for each construct at each time point are presented in online suppl. material 3. There was no significant heterogeneity between studies for any cognitive construct at any time point for the SRS studies. The meta-analysis suggests a relatively constant amount of patients experiencing cognitive decline over time after SRS, albeit with large confidence intervals (shown in Fig. 2b).

\section{Discussion}

The aim of this study was to systematically assess the current evidence on the cognitive changes across different cognitive constructs after either WBRT or SRS in adult patients with nonresected BMs with objective neurocognitive assessments performed at baseline and after treatment. Our meta-analysis indicates that after WBRT, the majority of patients show a decline in cognitive performance until midterm follow-up (5-8 months), whereas a subset of patients with relatively good outcome show stable cognitive performance in the long-term (9-15 months). For SRS, an initial dip (1-4 months) in cognitive performance in patients was observed by half of the studies, whereas at mid- and long-term follow-up, all studies reported that the majority of the patients performed at pre-treatment levels. Since cognitive decline was assessed relative to baseline performance, differences in cognitive performance prior to radiotherapy were accounted for and thus cannot explain the differences between WBRT and SRS. This suggests that while the cognitive side effects of SRS are transient, after WBRT patients can experience deterioration over a longer period of time. This especially holds for those patients with shorter survival. Thereby, this review points toward SRS resulting in lowest risks for cognitive adverse side effects in this already cognitively vulnerable patient population with limited survival. Since WBRT and SRS have resulted in comparable survival rates in selected groups of patients, it could even be suggested to totally abstain from WBRT in patients with a limited number of BMs [44]. However, sometimes WBRT is inevitable due to high number of metastases and current technical capabilities. The information provided by this review can be used in communicating risks to patients and aid patients in making educated (shared) treatment decisions toward maintaining optimal QoL.

A high percentage of patients already experience cognitive problems before starting radiotherapy treatment, with at least one out of every 2 patients with BMs demonstrating cognitive impairment on minimally one cognitive construct $[18,29,30]$. Baseline cognitive impairment was only significantly predicted by larger baseline BMs volume, even when considering other factors such as the number of previous chemotherapy regimens [38]. Thus, not only previous cancer treatments but also the BMs themselves exert a significant burden on cognitive functioning. This indicates, once again, that patients with BMs represent a vulnerable patient group in which further cognitive decline should be minimized when possible.

The majority of WBRT studies found a consistent decline in cognitive performance from baseline to shortterm follow-up with a further decrease in performance at midterm, with verbal L\&M, EF, and verbal fluency most often affected [18, 25, 26, 28, 33-40]. However, in a subgroup of patients with a better outcome (lower baseline $\mathrm{BMs}$ volume and long-term BMs survivors), stable or improved cognitive performance was observed at midterm $[25,28]$. Additionally, patients receiving HA-WBRT showed less cognitive decline than those receiving conventional WBRT with even stable performance on some cognitive constructs [26, 33, 41]. At long-term follow-up (9-15 months), cognitive performance either remained stable compared to midterm follow-up or returned to baseline values for most cognitive constructs $[18,25,40]$. Our meta-analysis confirmed these results; at short- and midterm follow-up an increase in the incidence of WBRT patients with cognitive impairment was found, while a (relatively) stable or even lower incidence was found in the long-term. This suggests that while some patients show a decline in cognitive performance up until midterm follow-up after WBRT, a (relatively) good outcome is often accompanied by stable cognitive performance over time. To illustrate, stronger reduction in tumor volume 4 months after WBRT was related to better preservation of cognitive performance over time [18, 36-38]. It is unclear whether the observed decline in cognitive performance is characteristic of the worse responders (i.e., patients with less tumor shrinkage) or that the good responders survive long enough to recover from this dip in performance. Nonetheless, the data suggest that for patients with a longer survival (at least 9-15 months), the benefits of WBRT radiotherapy outweigh the costs in the long term. Currently, the majority of patients do not (yet) survive long-term, despite improvements in life expectancy with the introduction of immunotherapies and targeted therapies [45-47]. While early delayed effects (1-4 months after WBRT) are generally considered to be transient, the cognitive decline traditionally characterized as a late delayed effect (5-9 months after WBRT) is thought to be progressive and irreversible [48]. Therefore, the cognitive decline found at short- and midterm should not be discounted against the possible stable long-term cognitive performance in those with a good survival and should be discussed with BMs patients during shared decision-making. However, better discernment of short and long survival should be included in evaluating this. 
Results regarding cognitive performance after SRS at short-term follow-up (1-4 months) were variable; approximately half of the included studies observed cognitive deterioration, most frequently for verbal L\&M, fine motor coordination, and EF [29, 31, 32, 42]. The other studies found no changes in cognition compared to baseline $[25,30,43]$. At both midterm (5-8 months) and longterm follow-up (9-12 months), all studies reported either stable or (slightly) improved cognitive performance compared to baseline [25, 29-32, 42, 43]. The meta-analysis largely confirms these results; a relatively stable incidence of patients with cognitive decline from baseline was observed up until long-term follow-up, albeit with large confidence intervals. The initial dip in cognitive performance in some of the patients could be attributed to an increase in peri-lesional edema which is sometimes observed shortly after SRS but is often resolved 6 months later [49]. Moreover, adjuvant systemic treatment will often be (re-)initialized shortly after SRS. The short-term side effects of systemic treatments could therefore be the cause of this initial dip, rather than the radiotherapy treatment. Conclusively, after SRS an initial, transient dip in cognitive performance can occur, but at mid- and longterm, the majority of patients will have returned to or remained at pre-radiotherapy cognitive levels.

Looking in more detail at the affected cognitive constructs, not one is specifically affected by WBRT or SRS. Rather, change in cognitive performance was observed across several cognitive constructs, including, but not limited to verbal L\&M, EF, information processing speed, and fine motor coordination, which have been linked to a wide range of neuroanatomical substrates involving both cortical areas and white matter networks [50-54]. This is supported by previous research indicating morphological changes after brain irradiation in both cortical structures (cortical thickness, gray matter volume, and gray matter density) as well as white matter networks [55-61]. Additionally, the amount of microstructural damage to white matter fibers has been shown to be directly associated with cognitive deterioration in cancer patients [62].

\section{Strengths and Limitations}

Cognitive functioning after cranial radiotherapy has been gaining research interest as reflected by the included studies (published between 2003 and 2020), with most studies (9/14) published over the last 5 years. Nonetheless, studying cognitive changes after radiotherapy in patients with BMs remains challenging for multiple reasons. First, different factors could influence cognitive functioning over the follow-up period, including tumor progression, adjuvant systemic treatment, or changes in mood. Additionally, a substantial number of patients drop out during the study period, most often due to high disease burden.
Especially in the long-term, results are therefore based on the small numbers of patients that are fit enough to stay compliant. Unfortunately, this is inevitable in this vulnerable patient population with limited overall survival.

Additionally, numerous challenges hinder in-depth comparison across studies, including differences in patient characteristics (e.g., age), disease characteristics (e.g., primary tumor type), and treatment characteristics (radiotherapy schedule) of the study populations. For example, 2 studies investigated HA-WBRT $(N=149)$, while all others investigated conventional WBRT. We chose not to exclude these since during HA-WBRT, less brain tissue is irradiated and including this in the review would lead to an underrepresentation rather than an overrepresentation of the cognitive damage to be expected after WBRT compared to SRS. Also, there was much heterogeneity across studies regarding both the methodology (e.g., definition for cognitive impairment and decline and timing of cognitive testing) and reported data (e.g., baseline cognitive data). To illustrate, most studies did not control for practice effects due to repeated testing over time and only 5 out of fourteen studies reported using parallel test for the repeated neuropsychological testing, even though cognitive assessment was repeated up to 9 times within a 1 -year period in some studies. These methodological shortcomings could have led to an underestimation of the cognitive changes after radiotherapy as cognitive problems might be masked by repeated testing effects. In order to aid comparability across studies, we chose to cluster the follow-up time points according to classifications used in previous studies. However, the subtle dynamics of cognitive change may not be ideally assessed by this classification. To illustrate, a difference in cognitive deteriorationfree survival of merely 0.7 months was found in favor of patients with resected BMs who received SRS (3.7 months) compared to WBRT (3 months) [63]. Thus, the time point clustering used in this study could have masked slight differences that are present between the SRS and WBRT patient groups.

The heterogeneity between studies was also reflected by our meta-analysis on the incidence of cognitive decline over time; the meta-analysis indicated significant heterogeneity between studies regarding the reported incidence of cognitive decline for L\&M at midterm for the WBRT studies. This could be explained by the fact that the definition used to assess cognitive change varied greatly between studies and, moreover, was not always reported. Additionally, the meta-analysis shows relatively broad confidence intervals due to the low number of patients for whom the data were available. Nonetheless, even with a small number of studies reporting the incidence of patients with cognitive decline, the meta-analysis indicated significant heterogeneity only for one type of radiotherapy, at one time point, and for one cognitive construct. 
In this review, 20 articles reporting on 14 original datasets were included. We chose to include all 20 articles since they answered different questions regarding cognitive functioning, thus did not present overlap. Results were summarized together per dataset to avoid overrepresentation of the same patients in this review. Strict inclusion criteria were used to minimize the potential confounding effects on cognitive performance (e.g., no resected BMs were included). Additionally, a critical appraisal was performed to ensure the quality of the data as reported in the article, which indicated that the majority of the included studies (75\%) was of good to high quality. Therefore, we believe our conclusions are warranted.

\section{Future Directions}

Currently, multiple single center trials are collecting and analyzing prospective data that will hopefully further improve our understanding of cognitive impairment after brain irradiation (e.g., [64-67]). Ideally, all future studies should at minimum use the neuropsychological tests recommended by the International Cancer and Cognition Task Force since these tests have been proven to be sensitive to the neurotoxic effects of cancer treatment [68]. A valuable line of research is to explore possible additional therapeutic strategies that could reduce treatment toxicity. As the mechanisms leading to radiationinduced cognitive impairment are multifactorial, several strategies, each addressing different mechanisms, have been proposed to potentially reduce the neurocognitive toxicity of radiation $[69,70]$. For example, avoiding highdose radiation on hippocampi and adding synthetic metallotexaphyrin motexafin gadolinium or memantine to WBRT have shown encouraging but mixed results [50, 51, 71-76]. These strategies provide promising prospects for the future, but do require further research.

\section{Conclusion}

This review indicates that after treatment with WBRT, most patients show declined cognitive performance until at least 8 months after treatment, after which those with a longer overall survival show stable cognitive performance. A proportion of SRS-treated patients first show a decline in cognitive performance, but the majority of the patients return to pre-treatment levels already 5 months after SRS and continue to display stable cognitive performance up until 1 year after SRS. It remains challenging to disentangle the effects of radiotherapy on cognitive functioning from the possible deleterious effects of systemic treatments, the effects of BMs themselves and patient's psychological state. Nonetheless, this current review indicates that while the cognitive side effects of SRS are transient, after WBRT patients can experience deterioration over a longer period of time. Thus, SRS will result in lowest risks for cognitive adverse side effects in this already (cognitively) vulnerable patient population with limited survival. This information can be used in communicating risks to patients and aid in making educated (shared) treatment decisions toward maintaining optimal QoL.

\section{Acknowledgment}

The authors want to thank the Faculty Liaison Medical Sciences of the University Library Utrecht for their support on developing the search strategy for this systematic review.

\section{Statement of Ethics}

An ethics statement is not applicable because this study is based exclusively on published literature.

\section{Conflict of Interest Statement}

The authors have no conflicts of interest to declare.

\section{Funding Sources}

At the time of writing this article, the first author received research funding from the Dutch Cancer Society "Koningin Wilhelmina Fonds (KWF)" Grant No. 11110.

\section{Author Contributions}

All authors contributed to the study design. E.E.G. and S.H.J.N. collected all data by screening of the manuscripts and extracting the relevant information. E.E.G. performed qualitative data analysis and S.H.J.N. performed statistical analyses. E.E.G. prepared the first draft of this manuscript. S.H.J.N., J.J.C.V., and M.E.J.Z. contributed and commented on the draft. All authors read and approved the final manuscript.

\section{Data Availability Statement}

Data from the published literature were used exclusively in this study. All the literature is referenced in the manuscript.

\section{References}

1 Barnholtz-Sloan JS, Sloan AE, Davis FG, Vigneau FD, Lai P, Sawaya RE. Incidence proportions of brain metastases in patients diagnosed (1973 to 2001) in the metropolitan detroit cancer surveillance system. J Clin Oncol. 2004 Jul;22(14):2865-72.

2 Barnholtz-Sloan JS, Yu C, Sloan AE, Vengoechea J, Wang M, Dignam JJ, et al. A nomogram for individualized estimation of survival among patients with brain metastasis. Neuro Oncol. 2012;14(7):910-8. 
3 Gaspar L, Scott C, Rotman M, Asbell S, Phillips T, Wasserman T, et al. Recursive partitioning analysis (RPA) of prognostic factors in three Radiation Therapy Oncology Group (RTOG) brain metastases trials. Int J Radiat Oncol Biol Phys. 1997 Mar;37(4):745-51.

4 Sperduto PW, Chao ST, Sneed PK, Luo X, Suh J, Roberge D, et al. Diagnosis-specific prognostic factors, indexes, and treatment outcomes for patients with newly diagnosed brain metastases: a multi-institutional analysis of 4,259 patients. Int J Radiat Oncol Biol Phys. 2010 Jul;77(3):655-61.

5 Eichler AF, Loeffler JS. Multidisciplinary management of brain metastases. Oncologist. 2007 Jul;12(7):884-98.

6 Khuntia D, Brown P, Li J, Mehta MP. Wholebrain radiotherapy in the management of brain metastasis. J Clin Oncol. 2006;24(8): 1295-304.

7 Mehta MP. The controversy surrounding the use of whole-brain radiotherapy in brain metastases patients. Neuro Oncol. 2015;17(7): 919-23.

8 Pinkham MB, Whitfield GA, Brada M. New developments in intracranial stereotactic radiotherapy for metastases. Clin Oncol (R Coll Radiol). 2015;27(5):316-23.

9 Grosshans DR, Meyers CA, Allen PK, Davenport SD, Komaki R. Neurocognitive function in patients with small cell lung cancer: effect of prophylactic cranial irradiation. Cancer. 2008 Feb;112(3):589-95.

10 Vardy J, Dhillon HM, Pond GR, Rourke SB, $\mathrm{Xu} \mathrm{W}$, Dodd A, et al. Cognitive function and fatigue after diagnosis of colorectal cancer. Ann Oncol. 2014 Dec;25(12):2404-12.

11 Mitchell T, Turton P. "Chemobrain": concentration and memory effects in people receiving chemotherapy: a descriptive phenomenological study. Eur J Cancer Care. 2011;20(4):539-48.

12 Griffith HR, Belue K, Sicola A, Krzywanski S, Zamrini E, Harrell L, et al. Impaired financial abilities in mild cognitive impairment: a direct assessment approach. Neurology. 2003 Feb;60(3):449-57.

13 Reid-Arndt SA, Yee A, Perry MC, Hsieh C. Cognitive and psychological factors associated with early posttreatment functional outcomes in breast cancer survivors. J Psychosoc Oncol. 2009;27(4):415-34.

14 Schimmel WCM, Gehring K, Eekers DBP, Hanssens PEJ, Sitskoorn MM. Cognitive effects of stereotactic radiosurgery in adult patients with brain metastases: a systematic review. Adv Radiat Oncol. 2018;3(4):568-81.

15 Tallet AV, Azria D, Barlesi F, Spano JP, Carpentier AF, Gonçalves A, et al. Neurocognitive function impairment after whole brain radiotherapy for brain metastases: actual assessment. Radiat Oncol. 2012;7:77.

16 Tsao MN, Rades D, Wirth A, Lo SS, Danielson BL, Gaspar LE, et al. Radiotherapeutic and surgical management for newly diagnosed brain metastasis(es): an American Society for Radiation Oncology evidence-based guideline. Pract Radiat Oncol. 2012;2(3):210-25.

17 Moher D, Shamseer L, Clarke M, Ghersi D, Liberati A, Petticrew M, et al. Preferred reporting items for systematic review and metaanalysis protocols (prisma-p) 2015 statement. Syst Rev. 2015;4(1):1-9.
18 Mehta MP, Rodrigus P, Terhaard CH, Rao A, Suh J, Roa W, et al. Survival and neurologic outcomes in a randomized trial of motexafin gadolinium and whole-brain radiation therapy in brain metastases. J Clin Oncol. 2003; 21(13):2529-36

19 Bray VJ, Dhillon HM, Vardy JL. Systematic review of self-reported cognitive function in cancer patients following chemotherapy treatment. J Cancer Surviv. 2018;12(4):53759.

20 Hutchinson AD, Hosking JR, Kichenadasse G, Mattiske JK, Wilson C. Objective and subjective cognitive impairment following chemotherapy for cancer: a systematic review. Cancer Treat Rev. 2012;38(7):926-34.

21 Lin NU, Wefel JS, Lee EQ, Schiff D, van den Bent MJ, Soffietti R, et al. Challenges relating to solid tumour brain metastases in clinical trials, part 2: neurocognitive, neurological, and quality-of-life outcomes. A report from the RANO group. Lancet Oncol. 2013 Sep; 14(10):e407-16.

22 Meyers CA, Rock EP, Fine HA. Refining endpoints in brain tumor clinical trials. J Neurooncol. 2012 Jun;108(2):227-30.

23 Meyers CA, Wefel JS. The use of the minimental state examination to assess cognitive functioning in cancer trials: no ifs, ands, buts, or sensitivity. J Clin Oncol. 2003;21(19): 3557-8.

24 Kirkpatrick JP, Wang Z, Sampson JH, McSherry F, Herndon JE, Allen KJ, et al. Defining the optimal planning target volume in imageguided stereotactic radiosurgery of brain metastases: results of a randomized trial. Int $\mathrm{J} \mathrm{Ra}$ diat Oncol Biol Phys. 2015;91(1):100-8.

25 Onodera S, Aoyama H, Tha KK, Hashimoto $\mathrm{N}$, Toyomaki A, Terae S, et al. The value of 4-month neurocognitive function as an endpoint in brain metastases trials. J Neurooncol. 2014;120(2):311-9.

26 Gondi V, Pugh SL, Tome WA, Caine C, Corn B, Kanner A, et al. Preservation of memory with conformal avoidance of the hippocampal neural stem-cell compartment during whole-brain radiotherapy for brain metastases (RTOG 0933): a phase II multi-institutional trial. J Clin Oncol. 2014;32(34):3810-6.

27 Bovi JA, Pugh SL, Sabsevitz D, Robinson CG, Paulson E, Mehta MP, et al. Pretreatment volume of MRI-determined white matter injury predicts neurocognitive decline after hippocampal avoidant whole-brain radiation therapy for brain metastases: secondary analysis of NRG Oncology Radiation Therapy Oncology Group 0933. Adv Radiat Oncol. 2019; 4(4):579-86

28 Saito H, Tanaka K, Kanemoto A, Nakano T, Abe E, Aoyama H. Factors affecting the baseline and post-treatment scores on the hopkins verbal learning test-revised Japanese version before and after whole-brain radiation therapy. Int J Mol Sci. 2016;17(11):1834.

29 Chang EL, Wefel JS, Maor MH, Hassenbusch SJ, Mahajan A, Lang FF, et al. A pilot study of neurocognitive function in patients with one to three new brain metastases initially treated with stereotactic radiosurgery alone. Neurosurgery. 2007;60(2):277-4.
30 Habets EJ, Dirven L, Wiggenraad RG, Verbeek-De Kanter A, Lycklama À NijeholtNijeholt GJ, Zwinkels $\mathrm{H}$, et al. Neurocognitive functioning and health-related quality of life in patients treated with stereotactic radiotherapy for brain metastases: a prospective study. Neuro Oncol. 2016;18(3):435-44.

31 Chang EL, Wefel JS, Hess KR, Allen PK, Lang FF, Kornguth DG, et al. Neurocognition in patients with brain metastases treated with radiosurgery or radiosurgery plus whole-brain irradiation: a randomised controlled trial. Lancet Oncol. 2009;10(11):1037-44.

32 Brown PD, Jaeckle K, Ballman KV, Farace E, Cerhan JH, Anderson SK, et al. Effect of radiosurgery alone vs radiosurgery with whole brain radiation therapy on cognitive function in patients with 1 to 3 brain metastases: a Randomized Clinical Trial. JAMA. 2016;316(4): 401-9.

33 Caine C, Deshmukh S, Gondi V, Mehta M, Tomé W, Corn BW, et al. CogState computerized memory tests in patients with brain metastases: secondary endpoint results of NRG oncology RTOG 0933. J Neurooncol. 2016 126(2):327-36

34 Cheng H, Chen H, Lv Y, Chen Z, Li CR. Prospective memory impairment following whole brain radiotherapy in patients with metastatic brain cancer. Cancer Med. 2018; 7(10):5315-21.

35 Deng X, Zheng Z, Lin B, Su H, Chen H, Fei S, et al. The efficacy and roles of combining temozolomide with whole brain radiotherapy in protection neurocognitive function and improvement quality of life of non-small-cell lung cancer patients with brain metastases. BMC Cancer. 2017;17(1):42.

36 Li J, Bentzen SM, Li J, Renschler M, Mehta MP. Relationship between neurocognitive function and quality of life after whole-brain radiotherapy in patients with brain metastasis. Int J Radiat Oncol Biol Phys. 2008;71(1) 64-70.

37 Li J, Bentzen SM, Renschler M, Mehta MP. Regression after whole-brain radiation therapy for brain metastases correlates with survival and improved neurocognitive function. J Clin Oncol. 2007;25(10):1260-6.

38 Meyers CA, Smith JA, Bezjak A, Mehta MP, Liebmann J, Illidge $\mathrm{T}$, et al. Neurocognitive function and progression in patients with brain metastases treated with whole-brain radiation and motexafin gadolinium: results of a randomized phase III trial. J Clin Oncol. 2004;22(1):157-65.

39 Zhan Y, Jiang X. Concomitant treatment of brain metastases with whole brain radiotherapy and temozolomide protects neurocognitive function and improve quality of life. Trop J Pharm Res. 2018;17(6):1209-13.

40 Zhu Y, Fu L, Jing W, Guo D, Kong L, Yu J. Effectiveness of temozolomide combined with whole brain radiotherapy for non-small cell lung cancer brain metastases. Thorac Cancer. 2018;9(9):1121-8.

41 Westover KD, Mendel JT, Dan T, Kumar K, Gao A, Pulipparacharuv S, et al. Phase II trial of hippocampal-sparing whole brain irradiation with simultaneous integrated boost (HSIB-WBRT) for metastatic cancer. Neuro Oncol. 2020;22(12):1831-9. 
42 Minniti G, Capone L, Nardiello B, El Gawhary R, Raza G, Scaringi C, et al. Neurological outcome and memory performance in patients with 10 or more brain metastases treated with frameless linear accelerator (LINAC)-based stereotactic radiosurgery. J Neurooncol. 2020; 148(1):47-55

43 van der Meer PB, Habets EJJ, Wiggenraad RG, Verbeek-de Kanter A, Lycklama À NijeholtNijeholt GJ, Zwinkels $\mathrm{H}$, et al. Individual changes in neurocognitive functioning and health-related quality of life in patients with brain oligometastases treated with stereotactic radiotherapy. J Neurooncol. 2018;139(2): 359-68.

44 Welzel G, Fleckenstein K, Schaefer J, Hermann B, Kraus-Tiefenbacher U, Mai SK, et al. Memory function before and after whole brain radiotherapy in patients with and without brain metastases. Int J Radiat Oncol Biol Phys. 2008;72(5):1311-8.

45 Gotwals P, Cameron S, Cipolletta D, Cremasco V, Crystal A, Hewes B, et al. Prospects for combining targeted and conventional cancer therapy with immunotherapy. Nat Rev Cancer. 2017;17(5):286-301.

46 Sperduto PW, Mesko S, Li J, Cagney D, Aizer A. Survival in patients with brain metastases : summary report on the updated diagnosisspecific graded prognostic assessment and definition of the eligibility quotient. J Clin Oncol. 2020;38(32):3773-84.

47 Roth P, Preusser M, Weller M. Immunotherapy of brain cancer. Oncol Res Treat. 2016; 39(6):326-34.

48 Makale MT, McDonald CR, Hattangadi-Gluth JA, Kesari S. Mechanisms of radiotherapyassociated cognitive disability in patients with brain tumours. Nat Rev Neurol. 2017 Dec; 13(1):52-64.

49 Le Rhun E, Dhermain F, Vogin G, Reyns N, Metellus P. Radionecrosis after stereotactic radiotherapy for brain metastases. Expert Rev Neurother. 2016;16(8):903-14.

50 Monje ML, Mizumatsu S, Fike JR, Palmer TD. Irradiation induces neural precursor-cell dysfunction. Nat Med. 2002 Sep;8(9):955-62.

51 Raber J, Rola R, LeFevour A, Morhardt D, Curley J, Mizumatsu S, et al. Radiation-induced cognitive impairments are associated with changes in indicators of hippocampal neurogenesis. Radiat Res. 2004 Jul;162(1):3947.

52 Braun U, Schäfer A, Walter H, Erk S, Romanczuk-Seiferth N, Haddad L, et al. Dynamic reconfiguration of frontal brain networks during executive cognition in humans. Proc Natl Acad Sci U S A. 2015;112(37):11678-83.

53 Duering M, Gonik M, Malik R, Zieren N, Reyes S, Jouvent E, et al. Identification of a strategic brain network underlying processing speed deficits in vascular cognitive impairment. Neuroimage. 2013;66:177-83.

54 Bressler SL, Kelso JA. Cortical coordination dynamics and cognition. Trends Cogn Sci. 2001;5(1):26-36.
55 Connor M, Karunamuni R, McDonald C, Seibert T, White N, Moiseenko V, et al. Regional susceptibility to dose-dependent white matter damage after brain radiotherapy. Radiother Oncol. 2017;123(2):209-17.

56 Lin J, Lv X, Niu M, Liu L, Chen J, Xie F, et al. Radiation-induced abnormal cortical thickness in patients with nasopharyngeal carcinoma after radiotherapy. Neuroimage Clin. 2017;14:610-21.

57 Nagtegaal SHJ, David S, van der Boog ATJ, Leemans A, Verhoeff JJC. Changes in cortical thickness and volume after cranial radiation treatment: a systematic review. Radiother Oncol. 2019;135:33-42.

58 Seibert TM, Karunamuni R, Kaifi S, Burkeen J, Connor M, Krishnan AP, et al. Cerebral cortex regions selectively vulnerable to radiation dose-dependent atrophy. Int J Radiat Oncol Biol Phys. 2017;97(5):910-8.

59 Simó M, Vaquero L, Ripollés P, GurtubayAntolin A, Jové J, Navarro A, et al. Longitudinal brain changes associated with prophylactic cranial irradiation in lung cancer. J Thorac Oncol. 2016;11(4):475-86.

60 Nagtegaal SHJ, David S, Snijders TJ, Philippens MEP, Leemans A, Verhoeff JJC. Effect of radiation therapy on cerebral cortical thickness in glioma patients: treatment-induced thinning of the healthy cortex. Neurooncol Adv. 2020;2(1):vdaa060.

61 Nagtegaal SHJ, David S, Philippens MEP, Snijders TJ, Leemans A, Verhoeff JJC. Dose-dependent volume loss in subcortical deep grey matter structures after cranial radiotherapy. Clin Transl Radiat Oncol. 2021;26:35-41.

62 Simó M, Vaquero L, Ripolles P, Jove J, Fuentes R, Cardenal F, et al. Brain damage following prophylactic cranial irradiation in lung cancer survivors. Brain Imaging Behav. 2016 Mar;10(1):283-95

63 Brown PD, Ballman KV, Cerhan JH, Anderson SK, Carrero XW, Whitton AC, et al. Postoperative stereotactic radiosurgery compared with whole brain radiotherapy for resected metastatic brain disease (NCCTG N107C/ CEC.3): a multicentre, randomised, controlled, phase 3 trial. Lancet Oncol. 2017; 118(8):1049-60.

64 El Shafie RA, Paul A, Bernhardt D, Hauswald $\mathrm{H}$, Welzel T, Sprave T, et al. Evaluation of stereotactic radiotherapy of the resection cavity after surgery of brain metastases compared to postoperative whole-brain radiotherapy (ESTRON)-a single-center prospective randomized trial. Neurosurgery. 2018 Sep;83(3): 566-73.

65 El Shafie RA, Paul A, Bernhardt D, Lang K, Welzel T, Sprave T, et al. Robotic radiosurgery for brain metastases diagnosed with either SPACE or MPRAGE sequence (CYBERSPACE): -a single-center prospective randomized trial. Neurosurgery. 2019 Jan;84(1): 253-60.
66 Grosu A, Frings L, Bentsalo I, Oehlke O, Brenner F, Bilger A, et al. Whole-brain irradiation with hippocampal sparing and dose escalation on metastases: neurocognitive testing and biological imaging (HIPPORAD) - a phase II prospective randomized multicenter trial (NOA-14, ARO 2015-3, DKTK-ROG). BMC Cancer. 2020;20(1):532.

67 Schimmel WCM, Verhaak E, Hanssens PEJ Gehring K, Sitskoorn MM. A randomised trial to compare cognitive outcome after gamma knife radiosurgery versus whole brain radiation therapy in patients with multiple brain metastases: research protocol CAR-study B. BMC Cancer. 2018;18(1):218.

68 Wefel JS, Vardy J, Ahles T, Schagen SB. International cognition and cancer task force recommendations to harmonise studies of cognitive function in patients with cancer. Lancet Oncol. 2011 Jul;12(7):703-8.

69 Wilke C, Grosshans D, Duman J, Brown P, Li J. Radiation-induced cognitive toxicity: pathophysiology and interventions to reduce toxicity in adults. Neuro Oncol. 2018;20(5): 597-607.

70 Rick O, Dauelsberg T, Kalusche-Bontemps EM. Oncological rehabilitation. Oncol Res Treat. 2017;40(12):772-7.

71 Tsai PF, Yang CC, Chuang CC, Huang TY, Wu YM, Pai PC, et al. Hippocampal dosimetry correlates with the change in neurocognitive function after hippocampal sparing during whole brain radiotherapy: a prospective study. Radiat Oncol. 2015;10(1):253.

72 Lin SY, Yang CC, Wu YM, Tseng CK, Wei $\mathrm{KC}$, Chu YC, et al. Evaluating the impact of hippocampal sparing during whole brain radiotherapy on neurocognitive functions: a preliminary report of a prospective phase II study. Biomed J. 2015;38(5):439-49.

73 Brown PD, Pugh S, Laack NN, Wefel JS, Khuntia D, Meyers C, et al. Memantine for the prevention of cognitive dysfunction in patients receiving whole-brain radiotherapy: a randomized, double-blind, placebo-controlled trial. Neuro Oncol. 2013;15(10):142937.

74 Mehta MP, Shapiro WR, Phan SC, Gervais R, Carrie $\mathrm{C}$, Chabot $\mathrm{P}$, et al. Motexafin gadolinium combined with prompt whole brain radiotherapy prolongs time to neurologic progression in non-small-cell lung cancer patients with brain metastases: results of a phase III trial. Int J Radiat Oncol Biol Phys. 2009; 73(4):1069-76.

75 Belderbos J, de Ruysscher D, de Jaeger K, Koppe F, Lambrecht M, Lievens Y, et al. Phase III randomized trial of prophylactic cranial irradiation with or without hippocampus avoidance in SCLC. SSRN Electron J. 2020. Epub ahead of print.

76 Brown PD, Gondi V, Pugh S, Tome WA, Wefel JS, Armstrong TS, et al. Hippocampal avoidance during whole-brain radiotherapy plus memantine for patients with brain metastases: phase III trial NRG oncology CC001. J Clin Oncol. 2020;38(10):1019-29. 